\title{
Engelli ve Engelli Olmayan Yüzücülerin Kendini Sabotaj ve Benlik Sayg1sı Düzeyleri
}

\author{
Yetkin Utku KAMUK ${ }^{1}$, Sevcan TÜZÜN² ve Semra DOĞAN ${ }^{3}$
}

\section{$\ddot{O}_{z}$}

Bu çalışmanın amacı, engelli ve engelli olmayan yüzücülerin kendini sabotaj ve benlik saygısı düzeylerinin incelenmesidir. Araştırmanın evrenini 2019 yll Bedensel Engelliler Türkiye Şampiyonası'na katılan yüzücüler ile Çorum ilindeki kulüplerde yarışan lisanslı yüzücüler, araștırma grubunu ise 64 engelli ve 138 engelli olmayan yüzücü $(n=202)$ olușturmaktadır. Gerekli etik kurul izni ve katulımciların yazılı onamları çalışma öncesinde alınmıştr. Verilerin toplanması için kişisel bilgi formu, Rhodewalt’ın (1990, s. 69-106) geliştirdiği ve Türkçe uyarlaması Akın (2012, s. 176) tarafindan yapılan "Kendini Sabotaj Ölçeği (KSÖ)" ile Rosenberg'in (1965, s. 16-38) geliştirdiği ve Türkçe'ye Tukuş (2010, s. 44-45) tarafindan uyarlanmış olan "Benlik Saygisı Ölçeği (BSÖ)" kullanılmıştır. Veriler normal dağılım göstermediğinden, gruplar arasındaki farkların incelenmesi için Mann-Whitney $U$ ve Kruskal-Wallis $H$ testleri kullanılmıştr. Korelasyon analizi için ise Spearman rho katsayısından faydalanılmıştır. İstatistiksel analizlerin sonuçlarına göre, engelli ve engelli olmayan yüzücülerin KSÖ ve BSÖ puanları arasında anlamlı bir fark olmadığı bulunmuştur. BSÖ ve KSÖ puanları arasındaki ilişki incelendiğinde, engelli yüzücülerin BSÖ puanları ile KSÖ puanları arasında orta düzeyde negatif yönlü bir ilişki olduğu, engelli olmayan yüzücülerde ise bu ilişkinin zayıf düzeyde olduğu bulunmuştur. Engelli sporcuların BSÖ puanlarının yüksek olduğu ve spor yapmanın engelli yüzücülerin KSÖ puanlarını olumlu etkilediği sonucuna ulaşılmıştr. Engelli bireylerin benlik saygısı düzeylerinin yükseltilmesini sağlamak amacıyla spor yapmaya teşvik edilmelerinin ve desteklenmelerinin faydalı olacağı değerlendirilmektedir.

Anahtar Kelimeler: Müsabaka, Özsayg1, Spor, Yüzme, Engelli

\section{Self-handicapping and Self-esteem Levels of Physically Handicapped and Healthy} Swimmers

\begin{abstract}
The aim of this study was to examine self-handicapping and self-esteem levels of physically handicapped and healthy swimmers. The population was the swimmers who participated in the Turkish Physically Handicapped Swimming Championship, and who were healthy active swimmers lived in Corum province. A total of 202 swimmers (64 physically handicapped and 138 healthy) participated in the study. Ethics committee approval and written informed consents of the participants were obtained prior to the study. A personal information questionnaire which was developed by the researchers, Rhodewalt's (1990, p. 69-106) SelfHandicapping Scale (SHS) which was adapted into Turkish by Akin (2012, s. 176), and Rosenberg's (1965, p. 16-38) Self-Esteem Scale (SES) which was adapted into Turkish by Tukus (2010, p. 44-45) were used to collect data. Mann-Whitney U and KruskalWallis $\mathrm{H}$ tests were used to examine the differences between/among the groups. Spearman's rho was used to analyze the relationships between the variables. As an outcome of the statistical analysis, it was found that there is no significant difference between the SHS and SES scores of the handicapped and healthy swimmers. Analysis of the correlation between the SHS and SES scores revealed that there was a moderate negative correlation between the SHS and SES scores of the handicapped swimmers. A weak and negative correlation was found for the healthy swimmers. As a result of the study, it was found that the SES scores of the physically handicapped swimmers were positively affected by being a swimmer and SES scores positively affected the SHS scores of that swimmers. It was concluded that encouraging and supporting handicapped individuals towards sports will be a great way to promote those individuals' self-esteem levels.
\end{abstract}

Key Words: Competition, Personal Worth, Sports, Swimming, Disabled

\section{Atıf İçin / Please Cite As:}

Kamuk, Y. U., Tüzün, S. ve Doğan, S. (2020). Engelli ve engelli olmayan yüzücülerin kendini sabotaj ve benlik sayg1sı düzeyleri. Manas Sosyal Araşttrmalar Dergisi, 9(4), 2577-2588.

Geliş Tarihi / Received Date: 14.06.2020

Kabul Tarihi / Accepted Date: 25.08.2020

\footnotetext{
1 Dr. Öğr. Üyesi - Hitit Üniversitesi Spor Bilimleri Fakültesi, Antrenörlük Eğitimi Bölümü, yetkinkamuk@hitit.edu.tr, ORCID: 0000-0001-5976-7503

2 Lisansüstü Öğrencisi - Hitit Üniversitesi Sağlık Bilimleri Enstitüsü, Beden Eğitimi ve Spor Anabilim Dalı, sevcantopgul@hotmail.com, ORCID: 0000-0001-9492-1473

3 Lisansüstü Öğrencisi - Hitit Üniversitesi Sağlık Bilimleri Enstitüsü, Beden Eğitimi ve Spor Anabilim Dalı, semracagan19@gmail.com, ORCID: 0000-0002-7981-8096
} 


\section{Giriş}

İnsanoğlu, hayatı boyunca pek çok duygu ve olay deneyimlemektedir. Bunların bir kısmı olumlu iken, bir kısmı da olumsuzdur. Bireylerin dünyayı algılamaları, deneyimleri doğrultusunda gerçekleşmektedir. Yaşanan zorluklar, acılar, sevinçler, başarılar gibi etmenler bireylerin kendilerine yönelik olarak algılarını etkiler. Bir performansın gerçekleştirilmesinde başarısız olunması durumunda, insanlar bunu bir yetersizlik ya da yeteneksizlik olarak değerlendirebilir ve böyle bir duruma düşmekten kaygilanabilirler. Bunun önüne geçebilmek için bireyler bazen, durumun hem kendisi hem de çevresi için rasyonelleştirilebilmesine olanak sağlayacak davranışlarda bulunabilirler (Büyükgöze ve Gün, 2015, s. 690). Böyle durumlarda, kendini sabotaj stratejilerinin kullanımı gerçekleşebilmektedir.

Kendini sabotaj, insanların gelecekte karşılaşabilecekleri olası bir başarısızlığa karşı uygun bir mazeret üretmek için önceden bazı davranışlar ortaya koymaları ya da bazı ifadelerde bulunma stratejileri olarak belirtilmektedir (Coudevylle, Ginis ve Famose, 2008, s. 392). Gelecekte gerçekleştirilecek bir görevin başarısız olma ihtimalinin gerçekleşmesi halinde, benlik saygısının zarar göreceğini düşünen bir birey, bu potansiyel başarısızlık durumunun gerçekleşmesi halinde, sorumluluğu ürettiği mazeretine yükleyerek başarısızlığının sebebini dışsal faktörlere bağlayabilir; performansın başarılı olarak tamamlanması halinde ise, birey önceden belirttiği mazeretlerin var olmasına karşın görevde başarı gösterebildiğini ispatlamış olur. Böylelikle, her iki durumda da kendini sabotaj davranışı, birey için fayda sağlar (Akın, Abacı ve Akın, 2011, s. 1158). Aslında, kendini sabotaj stratejilerini kullanan bireyler, başarısız olmak için çabalamazlar. Bunun ötesinde, eğer muhtemel başarısızlıklarını dışsallaştırabilir iseler, başarısız olma durumunu çekinmeden kabul ederler (Jones ve Berglas, 1978, s. 202). Kendini sabotaja yönelen bireyin yapmak istediği, işleri zora sokmak ve muhtemel bir başarısızlığa gerekçe olarak, kendi yaratmış olduğu gerçekçi olmayan nedenleri sunmaktır. İşlerin zorlaştırılması sayesinde kendini sabote etme davranışının tercih edilmesinin nedeni, suni olarak yaratılan "performansı zorlaşııııcı gerekçelerin" diğer insanlar tarafından çok fazla sorgulanmayacağ1 ve bu gerekçelerin toplum tarafindan kabul göreceğinin düşünülmesidir (Akın vd., 2011, s. 1159).

Kendini sabotaj davranışı iki şekilde ortaya çıkmaktadır. Birincisi, davranışsal kendini sabotajdır ve burada birey, gerçekleştirilecek görevin başarılı olmamasına neden olacak mazeretleri kasıtlı olarak üretir. $\mathrm{Bu}$ amaçla; başka işlere yönelme, alkol kullanımı, kendini gereksiz yere fiziksel olarak yorma gibi yollara başvurur. İkincisi, sözel kendini sabotajdır ve burada birey içerisinde bulunduğu durumu, koşulları ve çevresini kötüleyerek bunu sözel olarak etrafındakilere ve özellikle de başarısızlık durumunda kendisini sorumlu hissedeceği kişilerin kulağına gidebileceği şekilde ifade eder (Self, 1990, s. 38).

Bireyler kendini sabote edici davranışlara genellikle benlik kavramları ile ilgili bir değerlendirmenin yapıldığı durumlarda başvururlar. Diğer insanların beklentilerine ilişkin yüklemeler, kendini sabote eden bireylerde görülen en büyük endişelerdir. Bireyin performansının diğerlerince değerlendirileceği ve benlik saygılarının zarar görebileceği durumlarda, genellikle kendini sabote etme eğilimi artmaktadır (Self, 1990, s. 53). Kendini sabotaj ve benlik saygısı kavramları birbiriyle bağıntılı kavramlardır. Çünkü kendini sabotaja yönelimin sebeplerinin en önemlisi, bireyin benlik saygısını koruma ihtiyacıdır (Tice, 1991, s. 713).

Benlik saygısı, bireylerin kendilerini nasıl algıladıkları ve kendilerine yönelik olarak tutundukları pozitif ya da negatif tavir olarak ifade edilmektedir (Rosenberg, 1965, s. 14). Benlik saygis1, bireylerin kendi karakter yapıları hakkında sahip oldukları düşünceleri betimlemekte kullanılmaktadır (Özmenteş, 2014, s. 140). Benlik saygısı, özdeğerlendirmenin sonucu olarak ortaya çıkmaktadır. Bireylerin benlik saygılarının oluşmasını ve gelişmesini sağlayan faktör, yeterli olma ve değerli olma kavramları arasında var olan ilişkidir. Yeterli olma kavramı, karşılaşılan problemlerin çözümlenebilmesi için etkin bir davranış sergilenmesi ve önceden belirlenmiş hedeflere ulaşabilmek üzere bireyin harekete geçme ve süreci başarı ile tamamlayabilme becerisi olarak ifade edilmektedir. Değerli olma kavramı ise, iyi/kötü, doğru/yanlış gibi nesnel olmayan değerlendirmeleri içermektedir. Etkileşimde bulunulan bireylerden alınan geri dönütler kullanılarak benlik saygısı düzeyi değişebilmektedir (Körükçü, Gündoğan ve Ogelman, 2014, s. 1666).

Benlik saygısı ve kendini sabotaj eğilimi, pek çok faktörden etkilenmektedir. Bunlardan bir tanesi de bireyin toplumdaki sosyal rolüdür. Engelli bireyler toplum içerisinde "yetersiz" bireyler olarak görülmekte ve bu da engelli bireylerin benlik saygılarını etkilemektedir. Engelliliğin tanımı Dünya Sağlık Örgütü (World Health Organization, [WHO]) tarafindan "kişiden ya da bir bütün olarak vücuttan beklenilen normal aktivitelerin yerine getirilmesindeki eksiklik ya da sinurlllk." ve "bir yetersizlik. veya özür nedeni ile yasa, cinsiyete, sosyal ve kültürel faktörlere bağh olarak kişiden beklenen rollerin kastllanmast veya yerine getirilememesi" şeklinde yapılmaktadır (WHO, 2011, s. 3). Ancak toplum içerisinde engellilerin sosyal ilişkilerinin, kültürel, sanatsal 
ve sportif faaliyetlerine erişimlerinin engellenmesi, ilave bir engel durumu olarak karşımıza çıkmaktadır. $\mathrm{Bu}$ durum, engelli bireylerin toplumsal hayatın dışına itilmesi olarak ifade edilebilmektedir (Genç, 2015, s. 83).

Engelli ve engelli olmayan bireyler, herhangi bir fark olmaksızın eşit hak ve olanaklara sahiptirler fakat engelli bireyler için yapılan özel uygulamalar ve düzenlemeler, bazen engellilerin aldıkları hizmetin kalitesinin artmasına değil, toplumdan soyutlanmaya ve yalnızlaşmaya neden olmaktadır. Engelli olsun olmasın her insan toplumsal hayatın içerisine dahil olarak kendini gerçekleştirme ihtiyacı hissetmekte ve bu ihtiyacın karşılanamadığ durumlarda, bireyde yetersizlik duygusu gelişmektedir. Engelli bireylerde bu etki oldukça belirgin şekilde görülmektedir (Öztabak, 2017, s. 359). Kültürel, sanatsal ya da sportif faaliyetlere katılmak, engelli bireylerin kendilerini gerçekleştirme gereksinimlerinin karşılanması amacıyla işlev görmektedir.

Yüzme sporu, su içerisinde yapılması nedeniyle, yerçekimi etkisinin çok daha az hissedildiği ve performans esnasında iskelet kaslarının efektif bir şekilde çalıştı̆̆ bir spor dalıdır (Bozdoğan, 2006, s. 6). Yüzme, WHO tarafindan önerilen bir aktivitedir ve bu spor yalnızca sağlığın korunması amaciyla değil profesyonel olarak da uygulanmaktadır (WHO, 2010, s. 49). Yüzme, oldukça geniş bir yelpazedeki bireylere hitap eden, neredeyse tüm kategorilerdeki (genç/yaşlı, engelli/sağllklı, obez/normal vb.) bireyler için sağlı̆̆a katkıda bulunan fiziksel bir aktivitedir (Chase, Sui ve Blair, 2008, s. 151). Yüzme sporunun sağlık üzerindeki faydaları yalnızca fiziksel boyutta değil, aynı zamanda psikolojik, sosyal ve zihinsel boyutlarda da görülmektedir. Roma'da 1960 yllında bedensel engelliler için yüzme müsabakalarının ilk defa gerçekleştirildiği paralimpik olimpiyatlarından başlayarak, bedensel engelli yüzme müsabakaları yapılmakta ve Dünya Para Yüzme çatısı altında, Dünya Paralimpik Komitesi himayesinde olimpik bir spor branşı olarak sürdürülmektedir. Engelli yüzme hem kadınlar hem de erkekler için; serbest, kurbağa, kelebek, sırtüstü, karışık ve bayrak branşlarında yapılmaktadır (World Para Swimming, 2020). Suyun kaldırma kuvveti nedeniyle, bireylerin ağırlıklarının büyük bir kısmı su tarafindan taşınmakta ve bu şekilde engelli bireyler, su dışında olduğundan daha iyi bir şekilde hareket edebilme imkanına sahip olmaktadırlar. Böylelikle engelli bireyler, özellikle kardiyovasküler kapasite ve beceri bileşenlerinin geliştirilebilmesi için bu spordan yararlanmaktadırlar (Seyhan, 2019, s. 6). Engelli bireylerde yüzme sporunun vital kapasitenin artışında etkisinin olduğu, dinlenim nabız sayısında azalmaya yol açtığı ve solunum fonksiyonularında iyileşmeye neden olduğu bildirilmiştir (Hutzler vd., 1998, s. 176). Yukarıda verilen literatür bilgileri ışığında, bu çalsşmanın amacı, engelli ve engelli olmayan yüzücülerin kendini sabotaj ve benlik saygısı düzeylerinin incelenmesidir.

\section{Yöntem}

\section{Evren - Örneklem}

Çalışmanın evrenini, 2019 yılında yapılan Bedensel Engelliler Türkiye Şampiyonası'na katılan engelli yüzücüler ile Çorum ilinde yüzme antrenmanlarına devam eden lisanslı yüzücüler oluşturmaktadır. Örneklem grubu ( $n=202 ; 64$ engelli ve 138 engelli olmayan), evren içerisinden seçilen, evreni temsil etme yeteneğine sahip (Yazıcıŏglu ve Erdoğan, 2011, s. 87) ve çalışmaya katılmak için yazılı olur veren yüzücülerdir. Çalışma için gerekli etik kurul izni Hitit Üniversitesi Girişimsel Olmayan Çalış̧alar Etik Kurulu'ndan (2019-133) alınmıştır. Araştırmaya davet edilen ve katılımı kabul eden 18 yaş üstü deneklerden Bilgilendirilmiş Gönüllü Olur Formu'nu, 18 yaş altı deneklerin velilerinden ise Bilgilendirilmiş Veli/Vasi Olur Formu'nu imzalamaları istenmiş, yazılı olur vermeyen yüzücüler araştırmaya dahil edilmemiştir.

\section{Veri Toplama Araçları}

Araştırma kapsamında katılımcıların demografik bilgilerinin toplanması amacıyla, araştırmacılar tarafindan tasarlanan Kişisel Bilgi Formu kullanılmışır. Katılımcıların benlik saygısı ve kendini sabotaj puanlarının elde edilmesi amacıyla, Rosenberg (1965, s. 16-38) tarafından geliştirilmiş olan ve Tukuş (2010, s. 44-45) tarafindan Türkçeye uyarlanan 4'lü Likert tipinde, 10 maddelik Benlik Saygisı Ölçeği (BSÖ) ile Rhodewalt (1990, s. 69-106) tarafindan geliştirilen ve Türkçe uyarlaması Akın (2012, s. 76) tarafindan gerçekleştirilen 6'lı Likert tipinde 25 maddelik Kendini Sabotaj Ölçeği (KSÖ) kullanılmıştır. KSÖ'nde yer alan maddeler arasındaki korelasyon katsayıları 0,69 ile 0,98 arasında bulunmuştur. AFA sonucunda 25 maddelik ölçeğin toplam varyansın \%32'sini açıkladığı ve maddelerin tek boyutta toplandığı görülmüsstür. Ölçeğin faktör yüklerinin 0,34 ile 0,69 arasında değiştiği, madde toplam korelasyonu puanlarının ise 0,30 ile 0,63 arasında sıralandığı bulunmuştur. Doğrulayıcı faktör analizi sonucunda tek boyutlu modelin iyi uyum verdiği görülmüştür $\quad$ RMSEA $=0,037 ; \quad \mathrm{NFI}=0,98 ; \quad \mathrm{CFI}=0,99 ; \quad \mathrm{IFI}=0,99 ; \quad \mathrm{RFI}=0,97 ; \quad \mathrm{GFI}=0,97$; 
AGFI=0,94). KSÖ’nün iç tutarlılık güvenirlik katsayısı 0,90 ve test-tekrar test güvenirlik katsayısı ise 0,94'tür (Akın, 2012, s. 76). KSÖ'nden elde edilecek olan puan 0 ile 125 arasında değişmektedir ve medyan değeri 60 civarındadır (Rhodewalt, 1990, s. 79). BSÖ'nin iç tutarlılık Cronbach Alpha sayıları, olumlu boyut için 0,875 , olumsuz boyut için 0,853 ve bütünsel olarak ise 0,897 şeklinde bulunmuştur (Tukuş, 2010, s. 34). BSÖ puanları 10-40 aralığında olabilmektedir. Puanların yüksek olması benlik sayg1s1 düzeyinin yüksek, puanların düşük olması ise benlik saygısının düşük olduğunu ifade etmektedir (Rosenberg, 1965, s. 35).

\section{Verilerin Analizi}

İstatistiksel analizlerin gerçekleştirilmesinde SPSS 22.0 (IBM Corp., ABD) ticari yazıllımı kullanılmıştır. Verilere ait tanımlayıcı istatistiklerin gösterilmesi için ortalama, standart sapma ve ortanca değerler hesaplanmış; aritmetik ortalama ve standart sapma değerleri, AO ve SS formu kullanılarak gösterilmiştir. Doğru istatistiksel yöntemlerin seçilebilmesi amacıyla, elde edilen verilerin normal dağılıma uygunluğu test edilmiş ve bunun için Shapiro-Wilk testi ve Q-Q Plot grafiğinden faydalanılmıştır. Normal dağılım varsayımının karşılanmadığı bulunduğundan, çoklu grup karşılaştırmaları için Kruskal-Wallis $H$ testi ve ikili grup karşılaştırmaları için Mann-Whitney $U$ testi kullanılmıştır. Değişkenler arasındaki korelasyonun yönünün ve gücünün incelenmesi için ise Spearman rho $(\varrho)$ testi kullanılmıştır. İstatistiksel anlamlılık düzeyi tüm testlerde $p<0,05$ olarak belirlenmiştir.

\section{Bulgular}

Çalışmaya, Türkiye Yüzme Federasyonu bünyesinde lisanslı olan engelli ve engeli bulunmayan 202 sporcu gönüllü olarak katılım sağlamıştır. Deneklerin 96'sı erkek ve 106'sı kadındır. Deneklerin verilerine ilişkin tanımlayıcı istatistikler Tablo 1'de gösterilmiştir.

Tablo 1. Kathlimculara Ait Tammlaync Istatistikler

\begin{tabular}{|c|c|c|c|c|c|}
\hline Değişken & & $f$ & $\%$ & KSÖ Puanı (AO $\pm S S)$ & BSÖ Puanı $(A O \pm S S)$ \\
\hline \multirow[t]{2}{*}{ Cinsiyet } & Erkek & 96 & 47,52 & $51,45 \pm 13,43$ & $32,21 \pm 5,37$ \\
\hline & Kadın & 106 & 52,48 & $53,10 \pm 12,75$ & $32,40 \pm 5,50$ \\
\hline \multirow[t]{2}{*}{ Engel Durumu } & Engelli & 64 & 31,68 & $51,70 \pm 14,02$ & $31,42 \pm 6,20$ \\
\hline & Engelli değil & 138 & 68,32 & $52,60 \pm 12,65$ & $32,72 \pm 4,99$ \\
\hline \multirow[t]{3}{*}{ Okul Türü } & Devlet & 169 & 83,66 & $53,01 \pm 12,6$ & $32,41 \pm 5,19$ \\
\hline & Özel & 12 & 5,94 & $50,00 \pm 15,74$ & $30,67 \pm 7,00$ \\
\hline & Mezun & 21 & 10,40 & $48,10 \pm 14,86$ & $32,43 \pm 6,37$ \\
\hline \multirow[t]{4}{*}{ Yaşanılan Yer } & Büyükşsehir & 22 & 10,89 & $48,27 \pm 16,06$ & $30,68 \pm 7,39$ \\
\hline & İl & 172 & 85,15 & $52,88 \pm 12,67$ & $32,75 \pm 4,98$ \\
\hline & İlçe & 6 & 2,97 & $54,50 \pm 7,71$ & $25,50 \pm 4,89$ \\
\hline & Köy & 2 & 0,99 & $42,00 \pm 22,63$ & $32,50 \pm 6,36$ \\
\hline \multirow[t]{2}{*}{ Milli Sporcu } & Milli Sporcu & 14 & 6,93 & $55,86 \pm 14,87$ & $29,07 \pm 6,23$ \\
\hline & Milli Değil & 188 & 93,07 & $52,05 \pm 12,93$ & $32,55 \pm 5,30$ \\
\hline \multirow[t]{5}{*}{ Aile Aylık Geliri } & 2020 TL'den az & 21 & 10,40 & $53,90 \pm 14,09$ & $29,95 \pm 6,61$ \\
\hline & 2020-3500 TL & 106 & 52,48 & $51,44 \pm 12,28$ & $33,67 \pm 4,62$ \\
\hline & 3501-5000 TL & 46 & 22,77 & $52,57 \pm 15,02$ & $31,57 \pm 5,02$ \\
\hline & $5001-7000 \mathrm{TL}$ & 15 & 7,43 & $58,67 \pm 8,80$ & $29,13 \pm 5,57$ \\
\hline & 7001 TL ve üzeri & 14 & 6,93 & $48,93 \pm 13,61$ & $31,36 \pm 7,50$ \\
\hline \multirow[t]{3}{*}{ Baba Öğrenim Düzeyi } & İlkokul & 53 & 26,24 & $53,4 \pm 13,96$ & $32,08 \pm 5,74$ \\
\hline & Ortaokul & 51 & 25,25 & $52,24 \pm 10,69$ & $31,76 \pm 4,68$ \\
\hline & Lise & 98 & 48,51 & $51,78 \pm 13,77$ & $32,71 \pm 5,63$ \\
\hline \multirow{4}{*}{$\begin{array}{l}\text { Anne Öğrenim } \\
\text { Düzeyi }\end{array}$} & İlkokul & 78 & 38,61 & $53,72 \pm 13,95$ & $32,49 \pm 5,36$ \\
\hline & Ortaokul & 63 & 31,19 & $52,03 \pm 11,97$ & $32,63 \pm 4,87$ \\
\hline & Lise & 44 & 21,78 & $50,18 \pm 13,89$ & $31,70 \pm 6,35$ \\
\hline & Üniversite & 17 & 8,42 & $52,47 \pm 10,72$ & $31,82 \pm 5,38$ \\
\hline
\end{tabular}

Deneklerin \%31,68 ( $n=64)$ engelli, diğerleri ise $(n=138 ; \% 68,32)$ engeli olmayan bireylerdir. Eğitim düzeylerinin dağ 1 lımı incelendiğinde, deneklerin $\% 6,93$ ü $(n=14)$ milli sporcu olduğu diğerlerinin ise \%93,07 (n=188) milli sporcu olmadığ1 görülmektedir. Deneklerin büyük bir kısmının $(\% 83,66)$ devlet 
okulunda, \%5,94 (n=12) özel okulda öğrenim gördüğü ve geriye kalan denek sayısının \%10,40 (n=21) mezun olduğu görülmüştür. Yüzücülerin \%96'sından fazlası il ya da büyükşehirde yaşamaktadır (Tablo 1).

Tablo 2. Ölçeklerden Alınan Puanlarm Normal Dağ̊lıma Uygunluğunun Test Edilmesi

\begin{tabular}{lcc}
\hline & Benlik Saygısı Ölçĕ̆i Puanı & Kendini Sabotaj Ölçeği Puanı \\
\hline$n$ & 202 & 202 \\
Ortalama & 32,31 & 52,32 \\
Medyan & 33,0 & 54,0 \\
Standart Sapma & 5,42 & 13,07 \\
En düşük & 14,0 & 13,0 \\
En yüksek & 40,0 & 79,0 \\
Shapiro-Wilk İstatistiği & 0,97 & 0,96 \\
$p$ (Shapiro-Wilk) & $0,00^{*}$ & $0,00^{*}$ \\
\hline
\end{tabular}

$* p<0,01$

Tablo 2'de, BSÖ ve KSÖ puanlarına ait tanımlayıcı istatistikler verilmiştir. Tablodan da anlaşılacağı üzere, deneklerin BSÖ puanlar1 14 ile 40 arasında değişiklik göstermektedir ( $\mathrm{AO}=26,54, \mathrm{SS}=5,96$; medyan=33). KSÖ puanlarına bakıldığında, puanların 13 ile 79 arasında dağıldığı ve $A O=45,48$ ve $\mathrm{SS}=13,5$ (medyan=54) değerlerine sahip olunduğu anlaşılmaktadır.

Verilerin normallik varsayımını karşılayıp karşılamadıklarının incelenmesi için gerçekleştirilen Shapiro-Wilk testi sonuçlarına göre, deneklerin BSÖ ve KSÖ puanlarının normal dağılıma uygun olmadığ1 bulunmuş $(S-W<0,01)$ (Tablo 2 ) ve $Q-Q$ Plot grafiğinin incelenmesi ile de bu karar doğrulanmıştır (Grafik 1). Bu nedenle BSÖ ve KSÖ puanlarının gruplar arasında farklılık gösterip göstermediğinin incelenmesi için parametrik olmayan testlerden faydalanılmasına karar verilmiştir.
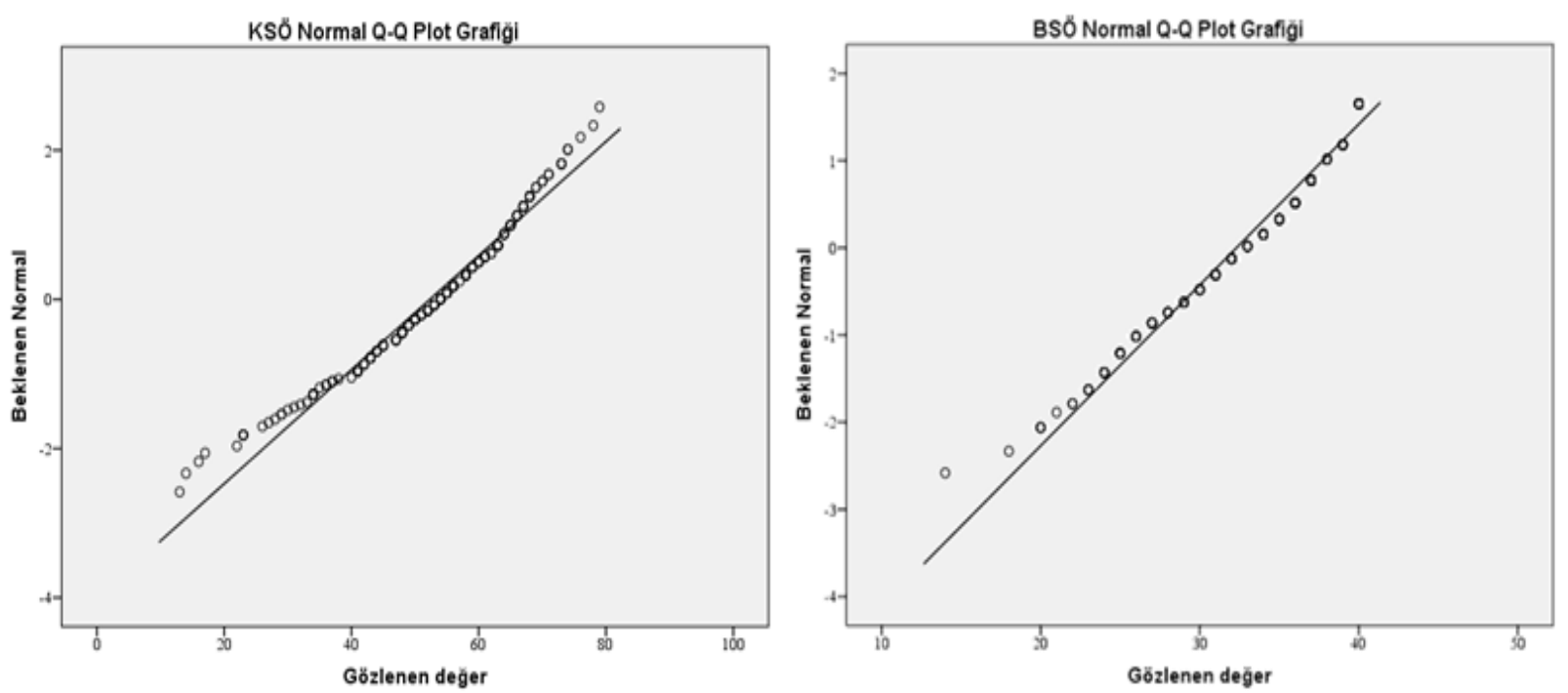

Grafik 1. KSÖ ve BSÖ Puanlarmın Normal Dă̆glıma Uygunluğunun Q-Q Plot İle Incelenmesi

Katılımcıların ölçeklerden aldıkları puanların kategorilere göre farklılık gösterip göstermediklerinin incelenmesi amacıyla gerçekleştirilen $M W U$ testinden elde edilen bulgulara göre, kendini sabotaj ölçeği puanlarının cinsiyet $\left(X_{(2)}^{2}=-1,30 ; p=0,19\right)$, engel durumu $\left(X_{(2)}^{2}=-0,25 ; p=0,81\right)$, sporculuk durumu $\left(X^{2}{ }_{(2)}=-1,07 ; p=0,28\right)$, öğrenim görülen okul tipi $\left(X^{2}{ }_{(2)}=-, 70 ; p=0,48\right)$ ve yaşanılan yer $\left(X^{2}{ }_{(2)}=-1,27 ; p=0,20\right)$ değişkenlerine göre farklılık göstermediği anlaşılmaktadır. Benlik saygısı ölçeği puanlarının ise sporculuk kategorisi hariç olmak üzere (milli/milli değil), hiçbir kategoride gruplar arasında farkllılk göstermediği bulunmuştur $(p>0,05)$. Milli sporcu ya da milli sporcu olmama durumu, kattlımciların benlik saygısı puanları üzerinde istatistiksel olarak anlamlı düzeyde etkiye sahiptir $\left(X_{(2)}^{2}=-2,15 ; p=0,03\right)$.

Tablo 4'te, çoklu gruplar için KSÖ ve BSÖ puanlarının farklarının Kruskal-Wallis $H$ testi ile analizi sonucunda elde edilen sonuçlar verilmiştir. Buna göre, katılımcıların KSÖ puanları arasında, katılım sağlanan müsabaka sayısı $\left(X_{(4)}^{2}=7,141 ; p=0,13\right)$, babanın öğrenim durumu $\left(X_{(2)}^{2}=0,988 ; p=0,61\right)$, babanın 
mesleği $\left(X_{(5)}^{2}=6,771 ; p=0,24\right)$, annenin öğrenim durumu $\left(X^{2}(3)=3,297 ; p=0,35\right)$, annenin mesleği $\left(X_{(5)}^{2}=3,190 ; p=0,67\right)$ ve ailenin gelir düzeyi $\left(X_{(4)}^{2}=6,033 ; p=0,20\right)$ değişkenlerine göre anlaml fark olmadığı bulunmuştur. Benzer şekilde, katılımcıların BSÖ puanları arasında da hiçbir kategoride istatistiksel olarak anlamlı fark yoktur $(p>0,05)$.

Tablo 3. Ölçek Puanlarmın Mann-Whitney U Testi İle İncelenmesi

\begin{tabular}{|c|c|c|c|c|c|c|c|}
\hline Ölçek & Kategori & $n$ & Sira Ortalaması & Siralar Toplamı & $M W U$ & $Z$ & $p$ \\
\hline \multirow{10}{*}{$\mathrm{KSÖ}$} & Erkek & 96 & 95,89 & 9205,0 & 4549,0 & $-1,30$ & 0,19 \\
\hline & Kadın & 106 & 106,58 & 11298,0 & & & \\
\hline & Engelli & 64 & 100,02 & 6401,5 & 4321,5 & $-0,25$ & 0,81 \\
\hline & Engelli değil & 138 & 102,18 & 14101,5 & & & \\
\hline & Milli sporcu & 14 & 117,68 & 1647,5 & 1089,5 & $-1,07$ & 0,28 \\
\hline & Milli değil & 188 & 100,30 & 18855,5 & & & \\
\hline & Devlet okulu & 169 & 91,73 & 15502,0 & 891,0 & $-0,70$ & 0,48 \\
\hline & Özel okul & 12 & 80,75 & 969,0 & & & \\
\hline & Büyükşehir & 22 & 86,52 & 1903,5 & 1650,5 & $-1,27$ & 0,20 \\
\hline & İl merkezi & 180 & 103,33 & 18599,5 & & & \\
\hline \multirow{10}{*}{ BSÖ } & Erkek & 96 & 100,24 & 9623,0 & 4967,0 & $-0,292$ & 0,77 \\
\hline & Kadin & 106 & 102,64 & 10880,0 & & & \\
\hline & Engelli & 64 & 93,87 & 6007,5 & 3927,5 & $-1,27$ & 0,21 \\
\hline & Engelli değil & 138 & 105,04 & 14495,5 & & & \\
\hline & Milli sporcu & 14 & 69,18 & 968,5 & 863,5 & $-2,15$ & $0,03^{*}$ \\
\hline & Milli değil & 188 & 103,91 & 19534,5 & & & \\
\hline & Devlet okulu & 169 & 91,87 & 15525,5 & 867,5 & $-0,84$ & 0,40 \\
\hline & Özel okul & 12 & 78,79 & 945,5 & & & \\
\hline & Büyükşsehir & 22 & 90,77 & 1997,0 & 1744,0 & $-0,91$ & 0,36 \\
\hline & İl merkezi & 180 & 102,81 & 18506,0 & & & \\
\hline
\end{tabular}

Tablo 4. Ölçeklerden Elde Edilen Puanlarn Kruskal-Wallis H Testi Ile Incelenmesi

\begin{tabular}{llllc}
\hline Ölçek & Değişkenler & $\boldsymbol{d f}$ & $\boldsymbol{\chi}^{\mathbf{2}}$ & $\boldsymbol{p}$ \\
\hline & Katıldığı müsabaka sayısı & 4 & 7,141 & 0,13 \\
& Baba ögrenim durumu & 2 & 0,988 & 0,61 \\
\multirow{3}{*}{ Kendini Sabotaj Ölçeği } & Baba mesleği & 5 & 6,771 & 0,24 \\
& Anne öğrenim durumu & 3 & 3,297 & 0,35 \\
& Anne mesleği & 5 & 3,190 & 0,67 \\
& Ailenin gelir düzeyi & 4 & 6,033 & 0,20 \\
\hline \multirow{5}{*}{ Benlik Saygisı Ölçeği } & Katıldı̆̆ı müsabaka sayıs1 & 4 & 8,242 & 0,08 \\
& Baba öğrenim durumu & 2 & 2,059 & 0,36 \\
& Baba mesleği & 5 & 10,416 & 0,06 \\
& Anne öğrenim durumu & 3 & 0,472 & 0,93 \\
& Anne mesleği & 5 & 5,426 & 0,37 \\
& Ailenin gelir düzeyi & 4 & 15,253 & 0,08 \\
\hline
\end{tabular}

Tablo 5. BSÖ ve KSÖ Puanlar Arasindaki İliskinin Spearman rho İle İncelenmesi

\begin{tabular}{llcc}
\hline & & KSÖ (Engelli yüzücüler) & KSÖ (Engelli olmayan yüzücüler) \\
\hline Benlik Sayg1sı Puanı & $\varrho(r b o)$ & $-0,47$ & $-0,26$ \\
& $p$ & $0,00^{*}$ & $0,00^{*}$ \\
& $N$ & 64 & 138 \\
\hline$* p<0,01$ & &
\end{tabular}


Katılımcıların BSÖ ve KSÖ puanları arasındaki ilişkinin incelenmesi için yapılan Spearman korelasyon analizi sonucunda, engelli yüzücülerin KSÖ puanları ile BSÖ puanları arasında orta düzeyde ve negatif yönde olacak şekilde, istatistiksel olarak anlamlı bir ilişkinin bulunduğu tespit edilmiştir $(\varrho=-0,47$, $p<0,01)$. Engelli olmayan yüzücüleri KSÖ ve BSÖ puanları arasındaki ilişkinin ise negatif yönde ancak zayıf düzeyde olduğu görülmektedir. $(\varrho=-0,26, p<0,01)$. Engelli yüzücülerin BSÖ puanları arttıkça KSÖ puanlarında azalma görüldüğü, aynı ilişskinin engelli olmayan yüzücüler için de var olduğu ancak engelli yüzücülere göre daha zayıf düzeyde gerçekleştiği bulunmuştur.

\section{Tartışma, Sonuç ve Öneriler}

Engelli ve engelli olmayan yüzücülerin kendini sabotaj ve benlik saygısı düzeylerinin incelendiği bu çalışmadan elde edilen bulgular sonucunda, engel durumlarının yüzücülerin kendini sabotaj ve benlik saygisı puanlarında fark yaratmadığı bulunmuştur. Literatür incelendiğinde, engelli bireylerin benlik saygısı düzeylerinin engelli olmayanlara göre daha düşük olduğunu bildiren çalışmaların mevcut olduğu görülmektedir. Açak ve Kaya (2015, s. 8) tarafindan yapılan bir çalışmada, işitme engelli futbolcuların benlik sayg1sı düzeylerinin engelli olmayanların benlik saygisı düzeylerinden daha düşük olduğu bulunmuştur. Benzer şekilde, Yüner (2018, s. 784) tarafindan yapılmış olan başka bir araştırmada, görme engelli bireylerin benlik saygısı düzeylerinin engelli olmayanların benlik saygısı düzeylerinden daha düşük olduğu, ancak aradaki bu farkın anlamlı olmaya yetecek miktarda olmadığı bulunmuştur. İşitme engelli ve görme engelli bireylerin benlik saygısı düzeylerinin, sağlıklı bireylere göre daha düşük olduğu bildirilmiştir (Amraei, Azizi, Khoshkhabar, Azizmazreah ve Fathi, 2017, s. 3). Benlik sayg1s1, bireyin kendine sayg1 duyduğu kadar kendisine karşı oluşturduğu tutumları ve kendisine verdiği değerleri de içermektedir. Bunlar; kendine güven duyması, önem vermesi, kendiyle barışık olması, kendini onaylaması, kendinden hoşnut olması, kendini pozitif ve sevilmeye layık bulması gibi kavramlardır (Roman, Cuestas ve Fenollar, 2008, s. 128).

İsitme engelli bireylerin benlik saygılarının araştırıldığı bir çalışmada, Jambor ve Elliot (2005, s. 63), farklı düzeyde işitme kayıplarına sahip bireylerin benlik saygısı puanlarının birbirinden farklı ve işitme kaybı yüksek olanların benlik saygılarının daha yüksek olduğunu bildirmişlerdir. Araştırmacılar bu durumun, ağır işitme kaybına sahip olan bireylerin işitme kayıplarını reddetme olasılıkların daha düşük olması ve kendilerini bu şekilde kabul etme olasılıklarının, daha az işitme kaybına sahip olan engelli bireylere kıyasla daha yüksek olması nedeniyle gerçekleştiğini öne sürmektedirler. Ayrıca, çok ağır işitme kaybına sahip olanların, durumlarını değiştirmek/düzeltmek için çaba vermek yerine, durumlarını kabullenerek mevcut koşullar altında hem profesyonel hem de kişisel olarak başarılı olma yollarına odaklandıklarını belirtilmektedir. Aynı araştırmanın sonuçlarına göre, kısmi işitme kaybı olanların, kendilerini iki dünya arasında kalmış gibi hissedebildikleri, kendilerini ne sağır ne de engelsiz olarak sınıflandırabildikleri ve kesin olarak ayrımı yapılamayan bu durumun, kısmi işitme engeline sahip olan bireylerin benlik kavramı arayışlarını etkileyerek ve benlik saygılarına zarar verdiği belirtilmiştir. Engelli sporcular ile sporcu olmayan engelli bireylerin benlik saygısı düzeylerinin karşılaştırıldı̆̆ı bazı çalışmalarda, spor yapmanın benlik sayg1sını olumlu yönde etkilediği ve spor yapan engellilerin benlik saygılarının sedanter engelli bireylerin benlik saygısı puanlarından anlamlı şekilde daha yüksek olduğu bildirilmiştir (Aslan, Aslan ve Uyan, 2017, s. 4032; Karakoç, Çoban ve Konar, 2012, s. 12; Naderi, Sakinehpoor, Farhadi ve Shabani, 2017, s. 1). Sportif aktivitelere katılımın, hafif düzey zihinsel engelli ergenlerin benlik sayg1sı düzeylerine etkilerinin araştırıldığ1 bir çalış̧mada, rekreasyonel düzeyde sportif aktivitelere katılımın benlik saygısı düzeylerini olumlu etkilediği bulunmuştur (Koçak, 2016, s. vi). Başka bir çalışmada ise, engel durumunun benlik saygısı üzerinde farka neden olmadığı, engelli ve engelli olmayan 18-25 yaş aralığındaki bireylerin benlik saygisı düzeylerinde fark olmadığı bulunmuştur (Bano, Anjum ve Pasha, 2015, s. 114). Kaner (2000, s. 18), ortopedik engelli ve engelli olmayan ergenler üzerinde yaptığı araştırma sonucunda, benlik saygisının engel durumuna göre farklılık göstermediğini bildirmiştir. Mevcut çalışma sonucunda elde edilen bulgular, literatürde yer alan farklı çalışmalardan elde edilmiş olan bulgular ile uyumludur. Engelli yüzücülerin görece daha düşük benlik saygisı puanlarına sahip olmalarının nedeninin, engellerinin kendilerini toplumsal yaşama katılmaktan alıkoyacak düzeyde olmamasına karşın, sağlıklı bireyler kadar hareket imkanına olamamaları ve Jambor ve Elliot (2005, s. 75) tarafindan belirtildiği üzere "iki dünya arasında kalmış" olduklarını düşünmelerinden dolayı kaynaklanmış olabileceği değerlendirilmektedir.

Diğer değişkenlerin benlik saygısı puanları üzerindeki etkileri değerlendirildiğinde, yalnızca "milli sporculuk" durumunun istatistiksel olarak anlamlı farka neden olduğu bulunmuştur. Elde edilen bulgulara göre, milli sporcu olan yüzücülerin benlik saygisı düzeyleri milli sporcu olmayan yüzücülerin benlik saygısı düzeylerinden daha düşüktür. Bu durumun, karşılaştırma yapılan grupların büyüklükleri arasındaki görece 
büyük farktan (milli sporcu sayısı=14, milli olmayan sporcu sayısı=188) kaynaklandığ1 ve bu farkın daha fazla sporcu ile tekrar çalışma yapılarak incelenmesi gerektiği düşünülmektedir.

Araştırmaya katılan yüzücülerin kendini sabotaj düzeylerinin incelenmesi sonucunda, engelli olmayan bireylerin kendini sabotaj puanlarının engelli bireylerin puanlarından daha yüksek olduğu ancak aradaki farkın istatistiksel olarak anlamlı olmaya yetecek düzeyde olmadığı bulunmuştur. Mevcut çalışmadan elde edilen bulgulara göre katıllımcıların KSÖ puanlarının medyan değeri 54'tür ve literatürde belirtilen değerin (medyan=60) altındadır. Literatürde yer alan çalışmalar incelendiğinde, engelli bireylerin kendini sabotaj düzeylerinin incelenmiş olduğu çalışmaların oldukça kısıtlı olduğu görülmüştür. İşitme engelli ve görme engelli bireylerin kendini sabotaj düzeylerinin incelendiği çalışmalarda, işitme engellilerin istatistiksel olarak anlamlı şekilde daha yüksek kendini sabotaj puanlarına sahip oldukları bulunmuştur (Amraei vd., 2017, s. 4; Mirzaee, Farahani, Heidari ve Amrai, 2011, s. 778). Kendini sabotaj; bir işi yapabilecek seviyede olduğu halde bu işi düzgün yapamayacağını düşünmek, bundan şüphe etmek ve kendinin yeterli seviyede olmadığını iddia ederek kendini haklı göstermek için çaba sarfetmek şeklinde ifade edilebilir (Üzar Özçetin ve Hiçdurmaz, 2016, s. 146). Engelli bireylerin herhangi bir işi yaparken başarısız olmaları durumunda, başarısızlıklarına mazeret olarak mevcut engellerini gösterebilmeleri mümkündür. Bu nedenle, benlik saygılarını korumak üzere davranışsal ya da sözel kendini sabotaj eğilimlerinin, engelli olmayan bireylerin eğilimlerinden daha düşük olması beklenebilir. Mevcut çalışmadan elde edilen bulgular hem engelli ve engelli olmayan bireylerin kendini sabotaj puanları arasında istatistiksel olarak anlamlı fark bulunmadığ1 bilgisiyle, hem de engelli olmayan bireylerin daha düşük kendini sabotaj puanlarına sahip olduğu bulgusunun engelli bireylerin kendini sabotaj yönelimlerine ilişkin literatür bilgileri ile uyum gösterdiğini ortaya koymuştur.

Mevcut çalışmada, katıllımcıların kendini sabotaj puanlarının, incelenmiş olan diğer değişkenlerin hiçbirinde anlamlı fark göstermediği bulunmuştur. Cinsiyete göre KSÖ puanlarına bakıldığında, cinsiyetler arasında istatistiksel olarak anlamlı bir fark olmamasına karşın, kadınların KSÖ puanlarının daha yüksek olduğu bulunmuştur. Cinsiyetin, kendini sabotaj düzeyi üzerinde anlamlı bir fark yaratmadığı daha önce yapılan çalışmalarda sıklıkla bildirilmiştir (Büyükgöze ve Gün, 2015, s. 697; Kalyon, Dadandı ve Yazıcı, 2016, s. 241; Tice, 1991, s. 714). Ancak cinsiyet değişkeninin kendini sabotaj düzeyini etkilediğini bildiren bazı çalışmalar da mevcuttur. Bu çalışmaların bir kısmında erkeklerin kendini sabotaj düzeylerinin kadınların kendini sabotaj düzeylerinden yüksek olduğu bulunmuş (Anl, Akın, Şar ve Eker, 2015, s. 165; Lucas ve Lovaglia, 2005, s. 237; Hirt ve McCrea, 2009, s. 264), başka çalışmalarda ise kadınların kendini sabotaj düzeylerinin daha yüksek olduğu belirtilmiştir (Yavuzer, 2015, s. 886; Weary ve Williams, 1990, s. 896). Dietrich (1990, s. 408) performans başarısını belirleyecek olan faktörün sosyal yeterlilik düzeyi olarak görülmesi halinde kadınların KSÖ puanlarının yüksek olacağını, akademik olarak yeterliliğin söz konusu olması halinde ise erkeklerin KSÖ puanlarının yüksek olacağını ifade etmiştir. Ancak buna alternatif olarak Lucas ve Lovaglia (2005, s. 239), toplumda daha yüksek bir sosyal statüye sahip olan erkeklerin, kendini sabotaj stratejilerine daha sık başvurarak toplumsal statülerini koruma davranışı gösterme eğiliminde olduklarını belirtmiştir. Elde edilen bulguların literatürde yer alan bilgiler ile karşılaştırılarak değerlendirilmesi sonucunda, cinsiyetin kendini sabotaj eğilimine etkileri üzerinde uzlaşılmış olmadığ1, içinde bulunulan duruma bağlı olarak cinsiyetin kendini sabotaj eğilimini etkilediği görülmüştür.

Kendini sabotaj davranışı ile benlik saygısı arasında bir ilişki mevcuttur. Literatürde, benlik saygısı ile kendini sabotaj eğilimi ilişkisini inceleyen çalışmalar bulunmaktadır. Bazı araştırmacılar bu iki kavram arasında negatif yönde bir ilişki olduğunu belirtmektedirler (Prapavessis ve Grove, 1998, s. 181; Warner ve Moore, 2004, s. 276). Benlik saygisı puanları kullanılarak kendini sabotaj düzeylerinin kestiriminin yapılabileceğinin bildirildiği çalışmalar da mevcuttur. Özgüngör ve Duatepe Paksu (2017, s. 111) kendini sabotaj düzeylerinin kestirimi için benlik saygısı puanlarının kullanılabileceğini ancak bunun benlik saygısı puanlarının düşük olması halinde geçerli olacağını belirtmektedirler. Mevcut çalışmada, katılımcıların benlik saygısı ve kendini sabotaj puanları arasındaki ilişki incelenmiş ve engelli yüzücülerin kendini sabotaj puanları ile benlik sayg1sı puanları arasında orta düzeyde ve negatif yönlü bir ilişkinin bulunduğu tespit edilmiştir. Engelli olmayan yüzücülerin puanları arasındaki ilişkinin de benzer şekilde, ancak zayıf düzeyde olduğu bulunmuştur. Engelli yüzücülerin benlik saygısı puanlarındaki artışın kendini sabotaj puanlarında azalmaya neden olduğu, engelli olmayan yüzücüler için ise bu durumun daha zayıf bir düzeyde gerçekleştiği tespit edilmiştir. Literatürde yer alan bilgiler ile karşılaş̧ırıldığında, elde edilmiş olan bulguların, iki kavram arasında negatif korelasyon olduğu bilgisiyle uyum içerisinde olduğu görülmektedir.

Mevcut çalısmadan elde edilen bulgular ve literatür bilgileri göz önüne alınarak değerlendirildiğinde, engelli ve engelli olmayan yüzücülerin kendini sabotaj ve benlik sayg1sı puanları arasında istatistiksel olarak 
anlamlı farka rastlanmadığı, kendini sabotaj puanlarında, incelenmiş olan değişkenlerin hiçbirinde farkın gözlenmediği, benzer şekilde benlik saygısı puanlarının da milli sporculuk durumu haricinde homojen yapıya sahip olduğu söylenebilir. Milli sporculuk durumunun benlik saygısı puanları üzerindeki etkisinin sağlıklı bir şekilde incelenebilmesi için yeterli eleman sayısına sahip olunmaması nedeniyle bu bulguya dikkatli bir şekilde yaklaşılması gerektiği sonucuna varılmıştır. Genel olarak, çalışmadan elde edilen bulguların, literatürde yer alan bilgiler ile uyum gösterdiği tespit edilmiştir.

Aynı engel kategorisinde olsalar dahi, engel şiddetlerinin farkına bağlı olarak, engelli bireylerin benlik saygisı düzeylerinde farklılıklar olabileceği değerlendirilmektedir. Bu nedenle, bundan sonra yapılacak olan benzer çalışmalarda, engel tipleri engel oranlarının da çalışmaya dahil edilmesi önerilmektedir. Bunun, engelli sporcuların benlik saygısı ve kendini sabotaj düzeylerinin betimlenmesi açısından fayda sağlayacağı düşünülmektedir.

Ayrıca, milli sporculuk durumunun benlik saygısı ve kendini sabotaj puanlanı üzerindeki etkilerinin daha sağlıklı bir şekilde incelenebilmesi için, milli sporcu sayısı ile milli sporcu olmayan sporcu sayısının birbirine yakın olduğu gruplar oluşturularak inceleme yapılması önerilmektedir.

Sedanter engellilerin BSÖ puanlarının düşük ve spor yapan engelli bireylerin BSÖ puanlarının ise yüksek olduğu literatürde birçok çalş̧mada gösterilmiştir. Engelli bireylerin sporun bu faydasından yararlanabilmelerinin sağlanması açısından, engelli bireylerin ilgili kurumlar tarafından spora yönlendirilmesi ve teşvik edilmesi; bu konuda malzeme, tesis ve erişim kolaylıklarının arttırılması yönünde çaba sarf edilmesi önerilmektedir.

\section{Etik Beyan}

"Engelli ve Engelli Olmayan Yü̈üü̈llerin Kendini Sabotaj ve Benlik. Saygısı Düzeyleri" başlıklı çalısmanın yazım sürecinde bilimsel kurallara, etik ve alıntı kurallarına uyulmuş; toplanan veriler üzerinde herhangi bir tahrifat yapılmamış ve bu çalısma herhangi başka bir akademik yayın ortamına değerlendirme için gönderilmemiştir.

\section{Kaynakça}

Açak, M. ve Kaya, O. (2015). İşitme engelli ve işitme engelli olmayan futbolcuların benlik saygıları ve saldırganlık düzeylerinin incelenmesi. Inönü Üniversitesi Beden Ë̆itimi ve Spor Bilimleri Dergisi, 2(2), 1-11.

Akın, A. (2012). Self-handicapping scale: a study of validity and reliability. Education and Science, 37(164), 176-187.

Akın, A., Abac1, R. ve Akın, U. (2011). Self-handicapping: a conceptual analysis. International Online Journal of Educational Sciences, 3(3), 1155-1168.

Amraei, K., Azizi, M. P., Khoshkhabar, A., Azizmazreah, H. ve Fathi, E. (2017). Difference between the students with visual and auditory impairment in self-handicapping. ERS Spectrum, 29(1), 1-6.

Anlı, G., Akın, A., Şar, A. H. ve Eker, H. (2015). Kendini sabotaj ile psikolojik iyi olma arasındaki ilişkinin çeşitli değişkenler açısından incelenmesi. Electronic Journal of Social Sciences, 14, 160-172.

Aslan, Ş., Aslan, U. B. ve Uyan, A. (2017). Spor yapma durumlarına göre bedensel engelli bireylerin benlik saygısının karşılaştırilması. International Journal of Human Sciences, 14(4), 4032-4040.

Bano, H., Anjum, N. ve Pasha, S. (2015). Differences in self-esteem of university students with and without disability. Journal of Educational Research, 18(1), 114-124.

Bozdoğan, A. (2006). Yǚme. İstanbul: Morpa Yayınları.

Büyükgöze, H. ve Gün, F. (2015). Araştırma görevlilerinin kendini sabotaj eğilimlerinin incelenmesi. Hitit Üniversitesi Sosyal Bilimler Enstitïsï Dergisi, 8(2), 689-704.

Chase, N. L., Sui, X. ve Blair, S. N. (2008).Comparison of the health aspects of swimming with other types of physical activity and sedentary lifestyle habits. International Journal of Aquatic Research and Education, 2(2), 151-161.

Coudevylle, G., Ginis, K. M. ve Famose, J. P. (2008). Determinants of self-handicapping strategies in sport and their effects on athletic performance. Social Behavior and Personality, 36(3), 391398.

Dietrich, D. (1995). Gender differences in self-handicapping: regardless of academic or social competence implications. Social Behavior and Personality, 23(4), 403-410.

Genç, Y. (2015). Engellilerin sosyal sorunları ve beklentileri. Sosyal Politika Calssmalan Dergisi, 15(35/2), 65-92.

Hirt, E. R. ve McCrea, S. M. (2009). Man smart, woman smarter? getting the root of gender differences in selfhandicapping. Social and Personality Psychology Compass, 3(3), 260-274.

Hutzler, Y., Chacham, A., Bergman, U. ve Szeinberg, A. (1998). Effects of a movement and swimming program on vital capacity and water orientation skills of children with cerebral palsy. Developmental Medicine \& Child Neurology, 40(3), 176-181.

Jambor, E. ve Elliot, M. (2005). Self-esteem and coping strategies among deaf students. Journal of Deaf Studies and Deaf Education, 10(1), 63-81. 
Jones, E. E. ve Berglas, S. (1978). Control of attributions about the self through self-handicapping strategies: the appeal of alcohol and the role of under achievement. Personality and Social Psychology Bulletin, 4(2), 200-206.

Kalyon, A., Dadandı, İ. ve Yazıcı, H. (2016). Kendini sabote etme eğilimi ile narsistik kişilik özellikleri, anksiyete duyarlllı̆̆ı, sosyal destek ve akademik başarı arasındaki ilişki. Düssïnen Adam Dergisi, 29, 237-246.

Kaner, S. (2000). Ortopedik engelli ve engelli olmayan erkek ergenlerde benlik sayg1sı ve beden imajı. Özel Eğitim Dergisi, 2(4), 13-22.

Karakoç, Ö., Çoban, B. ve Konar, N. (2012). İsitme engelli milli sporcular ile spor yapmayan işitme engellilerin benlik saygisı düzeylerinin karşılaştırlması. Selçuk Üniversitesi Beden Eğitimi ve Spor Bilim Dergisi, 14(1), 12-17.

Koçak, E. (2016). Zibinsel engelli ergenlerde sportif rekereasyon aktivitelerinin benlik sayggsina etkisi (Yüksek Lisans Tezi). Selçuk Üniversitesi Sağlık Bilimleri Enstitüsü. Konya.

Körükçü, Ö., Gündoğan, A. ve Ogelman, H. G. (2014). Okul öncesi eğitimi öğretmenliği lisans öğrencilerinin benlik sayg1sı ve empatik becerileri arasındaki ilişkilerin incelenmesi. Kastamonu Üniversitesi Kastamonu Eğitim Dergisi, 23(4), 1665-1678.

Lucas, J. W. ve Lovaglia, M. J. (2005). Self-handicapping: gender, race and status. Current Research in Social Psychology, 10(15), 234-249.

Mirzaee, M., Farahani, A., Heidari, M. ve Amrai, K. (2011). Comparing self-handicapping among blind and deaf students. Procedia Social and Behavioral Sciences, 15, 777-779.

Naderi, A., Sakinehpoor, A., Farhadi, V. ve Shabani, F. (2017). A comparative study of the comparison of quality of life and life satisfaction, self-esteem and social development between disabled athletes and non-athletes with disabilities. MEJDS, 7, 1-9.

Özgüngör S. ve Duatepe Paksu, A. (2017). Üniversite öğrencilerinde benlik saygısı düzeyine göre akademik başarıyı yordayan değişkenler. Türk Psikolojik Damssma ve Rebberlike Dergisi, 7(48), 111-125.

Özmenteş, G. (2014). Mesleki müzik eğitimi alan öğrencilerin müzik özyeterlikleri, benlik saygiları ve bireysel özellikleri arasındaki ilisskiler. Eğitim ve Bilim, 39(171), 138-152.

Öztabak, M. Ü. (2017). Engelli bireylerin yaşamdan beklentilerinin incelenmesi. Insan ve Toplum Bilimleri Dergisi, 9, 355-375.

Prapavessis, H. ve Grove, J. R. (1998). Self-handicapping and self-esteem. Journal of Applied Sport Psychology, 10(2), 175-184.

Rhodewalt, F. (1990). Introduction to individual differences in self-handicapping. Self Handicapping: The Paradox That Isn't. (Editörler: R. L. Higgins, C. R. Snyder, S. Berglas). New York: Plenum Press.

Roman, S., Cuestas, P. J. ve Fenollar, P. (2008). An examination of the interrelationships between self-esteem, others' expectations, family support, learning approaches and academic achievement. Studies in Higher Education 33(2), 127138.

Rosenberg, M. (1965). Society and the adolescent self-image. Princeton: Princeton University Press.

Self, E. A. (1990). Situational influences on self-handicapping. Self-Handicapping: The Paradox That Isn't. (Editörler: R. L. Higgins, C. R. Snyder, S. Berglas). New York: Plenum Press.

Seyhan, R. G. (2019). Bedensel engelli yüzüüülerinfizilesel uygunluk düzeyleri ile spora özgü performanslar arasmdaki ilişkinin belirlenmesi (Yüksek Lisans Tezi). Hacettepe Üniversitesi Sağllk Bilimleri Enstitüsü, Ankara.

Tice, D. M. (1991). Esteem protection or enhancement? Self-handicapping motives and attributions differ by trait self-esteem. Journal of Personality and Social Psychology, 60(5), 711-725.

Tukuş, L. (2010). Benlik saygussdeğerlendirme ölseğgi kessa formu Türkse güvenilirlik ve geçerlilik çalssması (Tipta Uzmanlık Tezi). Kocaeli Üniversitesi Tip Fakültesi, Kocaeli.

Üzar Özçetin, Y. S. ve Hiçdurmaz, D. (2016). Kendini sabote etme ve ruh sağllğ̆ üzerine etkisi. Psikiyatride Güncel Yaklaşmlar, 8(2), 145-154.

Warner, S. ve Moore, S. (2004). Excuses, excuses: self-handicapping in an Australian adolescent sample. Journal of Youth and Adolescence, 33(4), 271-281.

Weary, G. ve Williams, J. P. (1990). Depressive self-presentation: beyond self handicapping. Journal of Personality and Social Psychology, 58(5), 892-898.

World Health Organization (WHO). (2011). World report on disability. Malta: WHO Press.

World Health Organization (WHO). (2010). Global recommendations on physical activity for health. Geneva: WHO Press.

World Para Swimming. (2020). History of para swimming. Erişim Tarihi: 25 Temmuz 2020. Erişim adresi: https://www.paralympic.org/swimming/about\#: :text=HISTORY\%20OF\%20PARA\%20SWIMMING,coun tries $\% 20$ competed $\% 20$ in $\% 20$ the $\% 20$ sport.

Yavuzer, Y. (2015). Investigating the relationship between self-handicapping tendencies, self-esteem and cognitive distortions. Educational Sciences: Theory and Practice, 15(4), 879-890.

Yazıcıŏ̆lu, Y. ve Erdoğan, S. (2011). SPSS Uygulamal Bilimsel Arasttrma Yöntemleri. Ankara: Detay Yayıncilık.

Yüner, B. (2018). Örgüt temelli öz sayg1 ve örgütsel duygusal bağlllığa ilişkin öğretmen görüşleri. Ankara Üniversitesi Eğitim Bilimleri Fakültesi Özel Ë̆itim Dergisi, 19(4), 777-799.

\section{EXTENDED ABSTRACT}

Self-handicapping is defined as a strategy of behavior to create an appropriate excuse for a possible failure that they may encounter soon (Coudevylle, Ginis \& Famose, 2008, p. 392). In fact, individuals using self-handicapping strategies do not try to fail. Beyond that, if they can externalize their possible failures, they will accept the failure without hesitation (Jones \& Berglas, 1978, p. 202). Self-handicapping 
behavior occurs in two ways. The first is behavioral self-handicapping, where the individual intentionally produces excuses that will help the performance fail. For this purpose, the person may try to exhaust himself unnecessarily or postpone studying, etc. The second is self-reported self-handicapping and in this type of self-handicapping, the person expresses some types of excuses that will cause a potential verbally to those around him, and especially to those whom he feels responsible in case of failure. Individuals often resort to self-handicapping behaviors when an assessment will be made for themselves. In cases where the individual's performance is evaluated by the others and self-esteem can be damaged, the tendency to self-handicapping generally increases (Self, 1990, p. 53). The concepts of self-handicapping and self-esteem are correlated. Because the most important reason for using self-handicapping strategies is the need to protect the individual's self-esteem (Tice, 1991, p. 713).

Self-esteem is expressed as a positive or negative attitude towards themselves (Rosenberg, 1965, p. 14). Self-esteem emerges as a result of self-assessment. The factor that enables individuals to develop their self-esteem is the relationship that exists between the concepts of being adequate and valuable. The concept of being adequate is expressed as the ability of the individual to act effectively and to complete the process successfully in order to solve the problems encountered and to show an effective behavior. The concept of being valuable includes subjective evaluations such as good/bad, true/false. The level of self-esteem can be changed by using feedback from individuals with whom they interact (Körükçü, Gündoğan \& Ogelman, 2014, p. 1666).

Self-esteem and self-handicapping tendency are influenced by many factors. One of the factors is the social role of the individual in society. People with disabilities are seen as "inadequate" individuals in the society, which affects the self-esteem of individuals with disabilities. Swimming is an activity recommended by WHO and this sport is practiced not only for the purpose of health protection but also professional purposes (WHO, 2010, p. 49). Swimming is a physical activity that covers a wide range of individuals and contributes to health in almost all categories (young/old, disabled/healthy, obese/normal, etc.) (Chase, Sui \& Blair, 2008, p. 151). The health benefits of swimming are seen not only in physical dimension but also in psychological, social and mental dimensions. By having the literature information given above in mind, the aim of this study was to examine self-handicapping and self-esteem levels of handicapped and healthy swimmers.

A total of 202 swimmers (64 handicapped and 138 healthy) gave written consent to participate in the study. 96 of the subjects were male and 106 were female. Rosenberg's (1965, p. 16-38) Self-Esteem Scale (SES) and Rhodewalt's (1990, p. 69-106) Self-Handicapping Scale (SHS), and personal questionnaire were used as the data collection tools. Since the data was not normally distributed, the Kruskal-Wallis $H$ and Mann-Whitney $U$ tests were used for group comparisons. Spearman's tho was used to assess the correlation between variables.

It was found that the being handicapped or healthy did not make any difference in SES or SHS scores of swimmers. There are studies reporting that handicapped individuals have lower self-esteem levels than healthy individuals. The results of the current study are in line with the results from different studies in the literature. The reason that handicapped swimmers have relatively lower self-esteem scores may have been due to their limited mobility when compared to the healthy individuals. Although this limited mobility does not prevent them from participating in social life, they cannot move freely as the healthy people and because of that, they may think they are "stuck between two worlds" as stated by Jambor and Elliot (2005, p. 75).

The self-handicapping scores of the healthy individuals were higher than the scores of the handicapped people although the difference was not statistically significant. It was seen that the studies which assess the self-handicapping levels of handicapped individuals were limited. Results of the current study revealed that there was no statistically significant difference between self-handicapping scores of handicapped and healthy swimmers, and that the finding that handicapped individuals had lower selfhandicapping scores.

Although having the same type of handicapping category, the severity of the handicap may affect self-esteem levels of handicapped individuals. Therefore, for the similar studies that may be conducted in the future, it is suggested that the types and severity of the handicaps should be included. That was believed to be beneficial for assessing self-esteem and self-handicapping levels of athletes with different types of handicaps. 
In the literature, it was shown in many studies that the sedentary handicapped people's SES scores to be low and the scores of handicapped sportsmen to be high. In order to ensure handicapped individuals to take advantage of sports, encouragement of handicapped individuals to do sports by government and non-governmental organizations are thought to be useful. In this regard, it is recommended to strive to increase the number of the facilities, the amount of support equipment and the opportunity to access to those facilities. 